\title{
Potensi Batuan Induk Hidrokarbon Serpih Gumai Di Talang Padang, Kabupaten Tanggamus Propinsi Lampung
}

\author{
Listriyanto ${ }^{1}$ \\ Sugeng Widada ${ }^{2}$, Basuki Rahmad ${ }^{3}$, Salatun Said ${ }^{4}$, Hendaryono $^{5}$ \\ ${ }^{1}$ Staf Pengajar Prodi Teknik Perminyakan, Fakultas Teknik, Universitas Proklamasi 45 Yogyakarta \\ 2, 3, 4, 5 Staf Pengajar Jurusan Teknik Geologi, FTM, Universitas Pembangunan Nasional "Veteran” Yogyakarta \\ Coresponding author.email :listriyanto@up45.ac.id
}

\begin{abstract}
Abstrak
Identifikasi interval batuan yang mungkin berpotensi sebagai batuan induk merupakan langkah awal eksplorasi yang penting, oleh sebab itu perlu dilakukan penelitian tentang potensi batuan sedimen yang mengandung bahan organik dengan kadar tertentu, yang oleh panas dan waktu dapat menghasilkan hidrokarbon dalam bentuk minyak atau gas secara tepat. Penelitian ini bertujuan untuk mengidentifikasi fasies dan potensi batuan induk hidrokarbon Formasi Gumai di Talang Padang, Cekungan Sumatra Selatan.

Analisis geokimia guna mengetahui potensi dan kualitas batuan induk dilakukan pada serpih penyusun Formasi Gumai. Hasil analisis potensi dan kualitas Batuan Induk menunjukkan kandungan TOC 3,55 termasuk "sangat baik". Rock-Eval menunjukkan bahwa serpih berpotensi "sedang" sebagai batuan induk hidrokarbon (S2 = 4,32 kg/ton). Angka Ro ( $<0,6)$ menunjukkan tingkat pematangan hidrokarbon belum tercapai. Nilai HI yang relatif tinggi mencerminkan bahwa batuan ini jika mencapai kematangan akan cenderung menghasilkan minyak. Nilai HI antara 456 mgHC/g umumnya berasal dari kerogen tipe II yang secara dominan mengandung unsur organisme laut dan darat.
\end{abstract}

Kata kunci : fasies, batuan induk, potensi, kualitas, dan kematangan

\begin{abstract}
Identification of rock intervals that may have as a source rock potential is the important first step in exploration, therefore it is necessary to conducted research on the sedimentary rock containing organic matter which with a certain level of heat and time can produce hydrocarbons in the form of oil or gas. The objective of this study is to identify facies and hydrocarbon source rock potential of Gumai Formation on Talang Padang, South Sumatra Basin.

Geochemical analysis in order to determine the potential and quality of source rock was performed sample of Gumai shale. The analysis of potential and source rock quality showed TOC content 3.55\% indicating "very good" quality. Rock-Eval analisys show that the shale is lean as hydrocarbon source rock $(S 2=4.32 \mathrm{~kg} /$ ton). Ro (<0.6) indicate hydrocarbon maturation level has not been reached. relatively low values $\mathrm{HI}$ reflects that this rock will tend to produce oil and gas if it reaches maturation level. The values of HI between $456 \mathrm{mgHC} / \mathrm{g}$ are generally derived from type II kerogen which predominantly contain terrestrial and marine organism.
\end{abstract}

Keywords: facies, source rock, potential, quality, and maturity

\section{Pendahuluan}

Di Cekungan Sumatra Selatan, menurut beberapa peneliti seperti diuraikan oleh Ginger (1994) menyebutkan bahwa Formasi Talang Akar di Central Palembang Sub-Basin dan Jambi SubBasin berdasarkan beberapa data sumur telah dipercaya sebagai batuan induk potensial, di sumur Senyerang-1 misalnya, di bagian utara cekungan, nilai TOC Talang Akar bagian Atas bervariasi mencapai 36\% dengan nilai Hydrogen Index (HI) antara 200 dan $350 \mathrm{mgHC} / \mathrm{g}$. Di Area Benakat Gully nilai TOC serpih mencapai 5\% dan nilai HI pada rentang $110-400 \mathrm{mgHC} / \mathrm{g}$.

Potensi batuan induk secara setempat juga dijumpai pada serpih marin Formasi Gumai, beberapa sumur di cekungan bagian utara telah dilaporkan nilai TOC mencapai 8\% dan HI 350 mgHC/g. Hal ini membuka kemungkinan bahwa batuan selain Formasi Talang Akar dapat bertindak sebagai batuan induk.

Kualitas suatu batuan sebagai batuan induk hidrokarbon sangat ditentukan oleh fasies pengendapannya. Tujuan penelitian ini adalah untuk mengidentifikasi fasies dan potensi batuan induk hidrokarbon Formasi Gumai di Talang Padang, sekitar $60 \mathrm{~km}$ ke arah barat dari Kota Bandar Lampung (Gambar 1), lokasi ini terhadap Peta Geologi Lembar Bengkulu (P3G, 1992) dapat dilihat pada Gambar 2. Secara stratigrafis, Formasi Gumai (Tmg) diendapkan selaras di atas Formasi Talang Akar (Tmot) dan ditutupi oleh Formasi Air Benakat (Tma). Formasi Gumai ini terdiri serpih gampingan, napal, batulempung dengan sisipan batupasir, tufan dan batupasir gampingan. 


\section{Potensi Batuan Induk Hidrokarbon Serpih Gumai \\ Di Talang Padang, Kabupaten Tanggamus Propinsi Lampung}

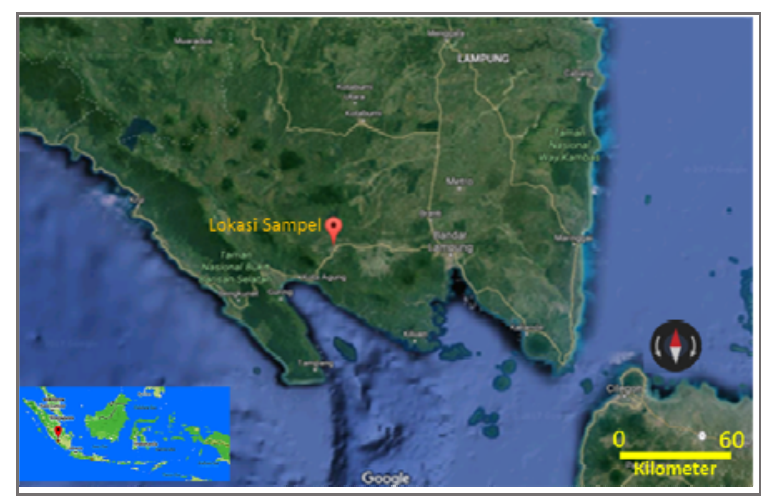

Gambar 1. Lokasi pengambilan sampel di Talang Padang (Google Earth, 2017)

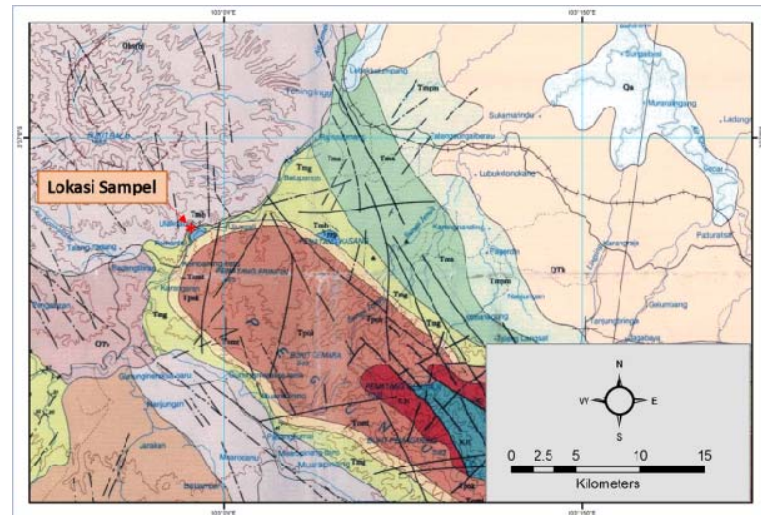

Gambar 2. Lokasi sampel pada Formasi Gumai (Tmg) di Talang Padang (P3G, 1992)

\section{Metodologi}

Metode yang digunakan dalam penelitian ini adalah analisis lapangan dan laboratorium. Analisis lapangan dilakukan untuk pengamatan profil dari singkapan guna menginterpretasikan fasies pengendapannya, kemudian mengambil sampel sebagai persiapan analisis laboratorium yang terdiri kandungan total karbon organik (TOC), dilakukan untuk sampel dengan nilai TOC> 0,50\%.yang kemudian diikuti oleh RockEval Pirolisis, dan kematangan.

\subsection{Preparasi sampel}

Preparasi dimaksudkan untuk memperoleh sampel bersih dengan mencuci menggunakan air dingin dan digerus hingga diperoleh ukuran fragmen sebesar kacang polong untuk persiapan kerogen atau ditumbuk halus untuk analisis kimia.

\subsection{TOC}

Kandungan karbon organik total dengan menghaluskan sampel, penanganan dilakukan secara hati-hati untuk melepaskan sebagian mineral karbonat menggunakan asam klorida hangat, dan menganalisis residu kandungan karbon dengan Leco Carbon Sulfur Determinator. Hal ini berlaku untuk parameter batuan induk bahwa sampel kurang dari $0,5 \%$ berat TOC tidak dapat menghasilkan hidrokarbon yang cukup secara komersial dan karena itu dianggap sebagai nonsource; sampel antara 0,5 dan $1 \%$ berat TOC dinilai sedang; sampel 1.0 dan $2 \%$ berat dinilai dianggap baik, sementara sampel lebih dari 2 sampai $4 \%$ dianggap sebagai sangat baik, dan bila lebih dari $4 \%$ berat dinilai istimewa (Peters \& Cassa, 1994).

\subsection{Rock Eval Pirolisis}

Pirolisis rock-eval dilakukan pada sampel batuan dimaksudkan untuk membedakan jenis bahan organik dan untuk mengevaluasi potensi batuan. Data dari hidrokarbon dinyatakan sebagai mg/g dengan parameter dasar sebagai berikut:

- S1 mewakili kuantitas minyak (hidrokarbons bebas) yang hadir pada batuan dan kira-kira analog dengan bitumen yang dapat diekstraksi dengan menggunakan pelarut.

- S2 merupakan jumlah hidrokarbon yang terbentuk oleh kerogen dalam sampel selama pirolisis antara suhu $300^{\circ} \mathrm{C}$ dan $600^{\circ} \mathrm{C}$.

- S3 adalah karbon dioksida yang dikeluarkan dari kerogen selama pirolisis.

- $\mathrm{T}_{\max }$, adalah temperatur puncak $\mathrm{S}_{2}$ dalam satuan ${ }^{\circ} \mathrm{C}$.

\subsection{Pantulan Vitrinit}

Analisa ini berdasarkan pada kemampuan daya pantul cahaya vitrinit. Kerogen yang telah matang akan membawa perubahan pada vitrinit dan hal ini akan diiringi dengan kemampuan partikel tersebut untuk memantulkan cahaya yang jatuh padanya. Kemampuan daya pantul ini merupakan fungsi temperature, artinya dengan perubahan waktu pemanasan dan temperatur menyebabkan warna vitrinit berubah di bawah sinar pantul.

Contoh batuan diletakkan di atas kaca preparat dan direkatkan dengan epoxyresin. Kemudian digosokkan dengan kertas korondum kasar sampai halus dan terakhir dengan menggunakan alumina. Selanjutnya contoh batuan tersebut diuji dalam minyak immersi (indeks bias $=1,516$ ) dengan menggunakan mikroskop dan suatu micro photomultiplier dan digital voltmeter attachment. Kemudian dilakukan kalibrasi terhadap vitrinit berdasarkan suatu standart yang terbuat dari gelas.

\section{Hasil dan Pembahasan}

\subsection{Fasies Pengendapan}

Berdasarkan profil singkapan di Talang Padang (Gambar 3) menunjukkan bahwa Formasi 
Gumai yang tersingkap di lokasi ini tersusun oleh perselang-selingan batupasir dan serpih yang menunjukkan suatu pola penebalan ke atas. Ciri batupasir pada profil ini adalah : berwarna coklat hingga coklat kehijauan, pasir halus sampai kasar, tersusun oleh kuarsa, feldspar, mika, glaukonit yang tersemen oleh silica. Strutur sedimen yang teramati adalah flaser, massif, dan laminasi parallel. Serpih pada singkapan ini menunjukkan warna abu-abu muda sampai abu-abu kecoklatan, bersifat karbonan, Tebal 2-3 meter.

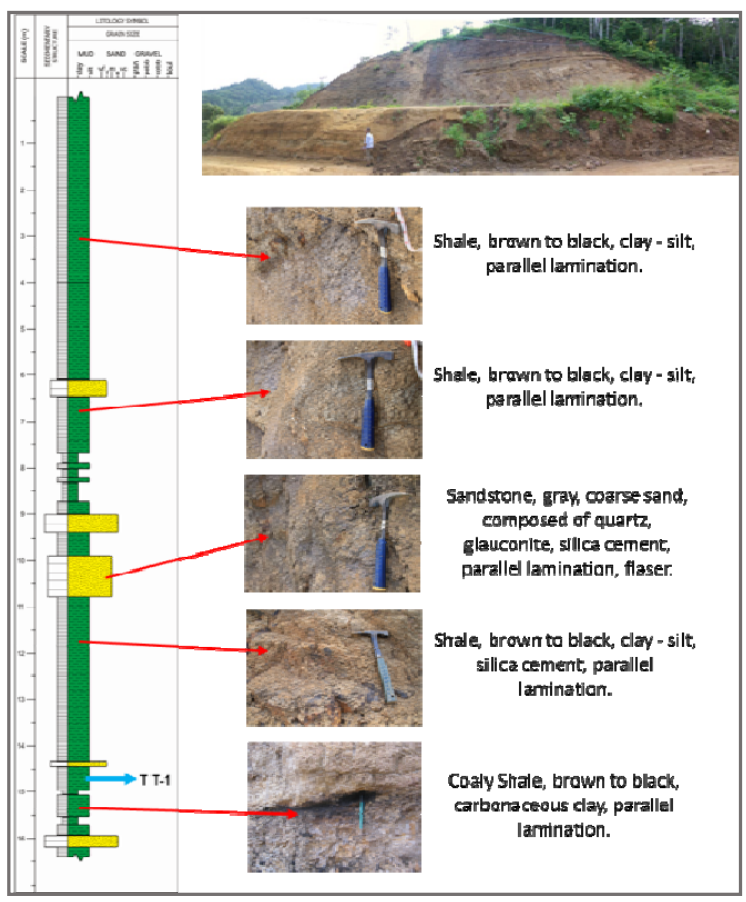

Gambar 3. Profil singkapan Formasi Gumai di Talang Padang

Keberadaan struktur flaser pada batupasir menunjukkan pengendapan terjadi pada daerah tidal flat karena pengaruh pasang surut (Dalrymple, 1992). keberadaan mineral mika pada batupasir menunjukkan proses sedimentasi terjadi pada kondisi kecepatan tinggi (Selley, 1985) yang biasa dijumpai pada lingkungkan delta. Dijumpainya mineral glaukonit menunjukkan adanya pengaruh marin pada saat pengendapan terjadi (Selley, 1985). Diketemukannya material karbonan menunjukkan adanya pengaruh asal darat pada pengendapan formasi ini. Dari penjelasan tersebut dapat disimpulkan bahwa pengendapan Formasi Gumai di lokasi ini terjadi pada daerah transisi, kemungkinan lingkungan delta yang dipengaruhi oleh proses pasang-surut (tidal dominated delta). Dominasi komposisi batuan berbutir halus (serpih) penyusun formasi ini menunjukkan proses pengendapan terjadi pada lingkungan delta bagian distal. yaitu delta pro. Kesimpulan itu juga diperkuat dengan dijumpainya mineral penunjuk lingkungan marin yaitu glaukonit.

\subsection{Analisis TOC}

Potensi batuan diperoleh dari analisis TOC dan Rock-Eval Pirolisis. Ringkasan analisis geokimia pada Tabel 1. Sampel terdiri serpih abuabu dan abu-abu kecoklatan, TOC yaitu 3,55\%, memiliki kuantitas baik untuk menghasilkan hidrokarbon.

Secara umum telah dapat diterima bahwa sampel dengan kandungan TOC $>0.5 \%$ mempunyai potensi yang cukup untuk menghasilkan minyak bumi secara komersial, oleh karena itu ditetapkan sebagai batuan induk. Sampel dengan kandungan TOC > 1.0\% mempunyai nilai yang cukup atau sedang sebagai batuan sumber, sedangkan untuk TOC antara 1.0\% - 2.0\% merupakan nilai di atas rata-rata (kaya) sebagai batuan induk Tabel 1. Berdasarkan hasil analisis di atas, sampel serpih di lokasi ini mempunyai nilai TOC sangat baik.

\subsection{Analisis Pirolisis}

Data yang diperoleh dari pirolisis Rockeval diinterpretasikan dengan cara berikut (Tissot dan Welte, 1984; Rad, 1984; Espitalie et al., 1985: Bordenave, 1993):

* S1 data tidak digunakan, kecuali pada nilai S1 tinggi yang terkait dengan nilai S2 rendah sehingga ditafsirkan sebagai adanya migrasi hidrokarbon.

* nilai S2 adalah indikator kualitas batuan :

$$
\begin{array}{ll}
\text { miskin } & <2,5 \mathrm{~kg} / \mathrm{ton} \\
\text { Sedang } & 2,5-5 \mathrm{~kg} / \mathrm{ton} \\
\text { Baik } & \mathrm{S} 2>5 \mathrm{~kg} / \mathrm{ton}
\end{array}
$$

* Tingkat kematangan ( $\mathrm{T}_{\max }$ ) bahan organik didefinisikan dengan :

$$
\begin{array}{ll}
\text { tidak matang } & <435^{\circ} \mathrm{C} \\
\text { matang } & 435^{\circ} \mathrm{C}-470^{\circ} \mathrm{C} \\
\text { lewat matang } & >470^{\circ} \mathrm{C}
\end{array}
$$

- Production Index (PI) digunakan untuk sampel dengan kekayaan yang sedang atau baik, terkait dengan nilai $\mathrm{T}_{\max }$ sebagai berikut:

$\begin{array}{ccl}\underline{\mathrm{T}}_{\max } & \underline{\mathrm{PI}} & \text { Kematangan } \\ <435^{\circ} \mathrm{C} & <0.1 & \text { Belum matang } \\ >435^{\circ} \mathrm{C} & 0.1-0.2 & \text { Awal matang } \\ & >0.2 & \text { Telah } \\ & & \text { terkontaminasi }\end{array}$




\section{Potensi Batuan Induk Hidrokarbon Serpih Gumai \\ Di Talang Padang, Kabupaten Tanggamus Propinsi Lampung}

* Kualitas batuan induk (hydrocarbon prone) juga dapat dideterminasi menggunakan hydrogen index (HI) sebagai berikut :

$\begin{array}{cc}\text { Source Quality } & \text { HI (mgHC/g TOC } \\ \text { Oil-prone } & >300 \\ \text { Gas-oil prone } & 200-300 \\ \text { Gas prone } & 110-200 \\ \text { Non-source } & <100\end{array}$

Diagram rinci untuk menafsirkan hasil analisis pirolisis dapat dilihat pada Tabel 1 dan Gambar 4. Hasil analisis pirolisis rock-eval menunjukkan bahwa sampel TT-1 dengan nilai S1 $1,09 \mathrm{mg} / \mathrm{g}$, sedangkan kandungan kerogen (S2) > $0,25 \mathrm{mg} / \mathrm{g}$ batuan, merupakan nilai-nilai yang dikategorikan "sedang" sebagai batuan potensial untuk menghasilkan hidrokarbon ketika mencapai tahap tingkat kematangan termal, sehingga cenderung menunjukkan potensi sebagai batuan induk hidrokarbon

Tabel 1. Pirolisis Rock-Eval Formasi Gumai di Talang Padang

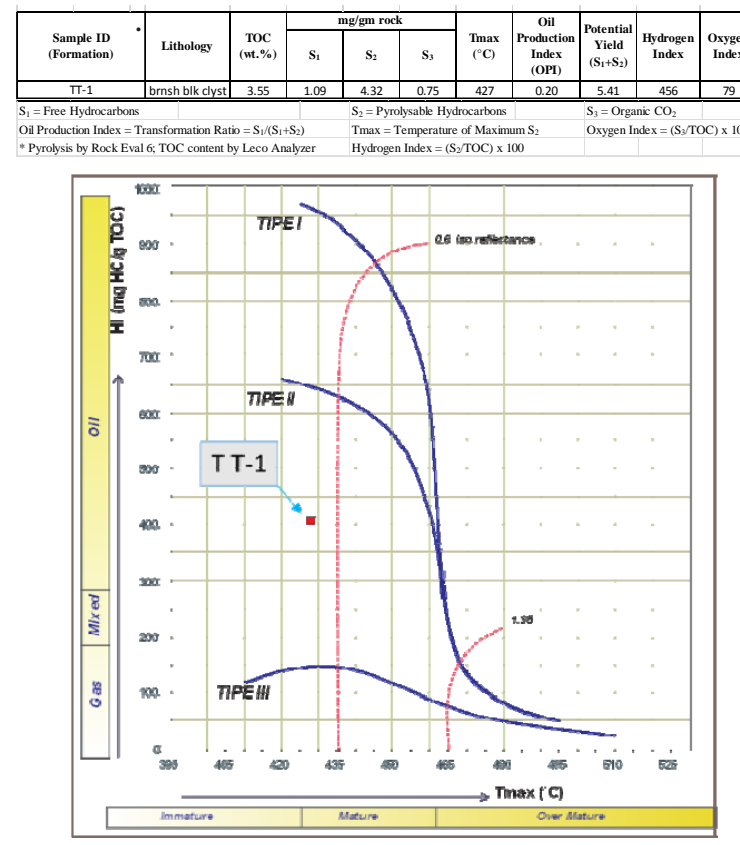

Gambar 4. Tipe Kerogen cross plot Tmax-HI menunjukkan kerogen tipe II

\subsection{Pantulan Vitrinit}

Dalam Penelitian ini Preparasi dan pengukuran dilakukan dengan Australian Standard 2856 (1986) and ASTM (2009), dari sampel diperoleh hasil pengukuran sebagai berikut :

Standard Deviation (\%) : $\quad 0,01$

Maximum Reflectance (\%) : 0,40

Minimum Reflectance (\%) : 0,36

Mean Reflectance (\%) : $\quad 0,38$
Parameter yang digunakan untuk menentukan tingkat kematangan berdasarkan pantulan vitrinit ditunjukkan pada Tabel 2.

Pantulan vitrinit yang dihasilkan menunjukkan bahwa harga rata-rata adalah $0,38 \%$. Data tersebut menunjukkan bahwa batuan induk pada Formasi Gumai di lokasi ini belum bisa menggenerasikan hidrokarbon.

Tabel 2. Kisaran kematangan Hidrokarbon berdasarkan angka pantulan Vitrinit (Peters \& Cassa, 1994)

\begin{tabular}{|c|c|}
\hline Ro (\%) & $\begin{array}{c}\text { Stage of Thermal } \\
\text { Maturity for Oil }\end{array}$ \\
\hline $0,2-0,6$ & Immature \\
\hline $0,6-0,65$ & Early mature \\
\hline $0,65-0,9$ & Peak mature \\
\hline $0,9-1,35$ & Late mature \\
\hline$>1,35$ & Post Mature \\
\hline
\end{tabular}

\subsection{Tipe Kerogen}

Secara individu sampel TT-1 memiliki nilai HI $456 \mathrm{mg} \mathrm{HC} / \mathrm{g}$ TOC, data tersebut menunjukkan bahwa sampel memiliki kemampuan untuk menghasilkan hidrokarbon. Dari cross-plot (Gambar 4) juga menunjukkan bahwa kerogen pada sampel ini termasuk tipe II yang memiliki kecenderungan membentuk minyak dan gas.

\subsection{Kematangan Termal}

Sampel menunjukkan nilai S2 yang dapat dianggap memenuhi syarat membentuk hidrokarbon, Tmax dianggap dapat diandalkan untuk menyimpulkan kematangan termal, tetapi sampel memiliki nilai $\operatorname{Tmax}<435^{\circ} \mathrm{C}$, kondisi ini cenderung menunjukkan tingkat sedimen yang belum matang. Pemeriksaan mikroskopis menunjukkan bahwa sampel memiliki nilai Ro rata-rata $0,38 \%$ yang mengindikasikan belum mencapai tahap kematangan termal (Robert, 1988, dalam Bordenave, 1993). Nilai PI dominan 0,2 (Tabel 1) menunjukkan awal tingkat kematangan termal, tetapi nilai-nilai PI tidak dapat diandalkan untuk penentuan tingkat kematangan dari sudut pandang analisis geokimia, nilai PI tinggi dalam sampel bahan organik Ro rendah tidak mencerminkan tingkat kematangan.

\section{Kesimpulan}

a. Formasi Gumai yang tersingkap di lokasi telitian diendapkan pada lingkungan delta pro.

b. Potensi batuan induk, hasil analisis TOC dan Rock Eval menunjukkan bahwa sampel Formasi Gumai dari daerah telitian di Talang Padang sampel TT-1 tidak berpotensi. 
c. Tingkat Kematangan Termal sedimen dari Formasi Gumai yang dianalisis tingkat belum matang, Ro rata-rata sampel 0,38\%.

d. Tipe Bahan Organik, batuan sedimen mengandung hidrogen yang umumnya mencerminkan bahwa kerogen terkandung yang adalah Tipe II dengan kapasitas cenderung menghasilkan minyak.

\section{Daftar Pustaka}

Bordenave, M. L. (ed.), 1993. Applied Petroleum Geochemistry. Editions Technip, France, 524pp.

Dalrymple, R. W., 1992, Tidal depositional System, in Walker, R.G., and NP James, Facies Model, Rrespons to Sea Level Change, Geol. Association, Canada.

Ginger, D., Fielding, K., 2005. The Petroleum Systems and Future Potential of The South Sumatra Basin, Proceedings, Indonesian Petroleum Association, Thirtieth Annual Convention \& Exhibition.

Peters, K.E., 1986. Guidelines for evaluating petroleum source rock using programmed pyrolysis. American Association of Petroleum Geologists, Bulletin, 70, p.318-329.

Tissot, B.P. dan Welte, D.H., 1984. Petroleum Formation and Occurrence, Edisi Kedua, Springer-Verlag, Berlin, $699 \mathrm{~h}$.

Gafoer, S., Amin, T.C., Pardede, R., 1992. Geological Map of The Bengkulu Quadrangles, Sumatra, Scale 1:250.000, Geological Research and Development, Bandung.

Selley, R.C., 1985, Ancient Sedimentary Environments, Third Edition. Cornell University Press, New York

Waples, D.W., 1985. Organic Geochemistry for Exploration Geologist. International Human Resources Development Corp., Boston, $232 \mathrm{~h}$. 